\title{
A review of shale pore structure evolution characteristics with increasing thermal maturities
}

\author{
Zhiye Gao ${ }^{1,2 \oplus *}$, Yupeng Fan ${ }^{1,2}$, Qixiang Xuan ${ }^{1,2}$, Guowei Zheng ${ }^{1,2}$ \\ ${ }^{1}$ State Key Laboratory of Petroleum Resources and Prospecting, China University of Petroleum, Beijing 102249, P. R. China \\ ${ }^{2}$ Unconventional Petroleum Research Institute, China University of Petroleum, Beijing 102249, P. R. China
}

Keywords:

Pore structure evolution organic matter pores

thermal simulation experiments

Cited as:

Gao, Z., Fan, Y., Xuan, Q., Zheng, G. A review of shale pore structure evolution characteristics with increasing thermal maturities. Advances in Geo-Energy Research, 2020, 4(3): 247-259, doi: 10.46690/ager.2020.03.03.

\begin{abstract}
:
Pore structure has a significant effect on the occurrence state of shale hydrocarbons and the hydrocarbon storage capability of shale reservoirs. Consequently, it is quite meaningful to clarify the shale pore structure evolution characteristics for understanding the migration and enrichment mechanisms of hydrocarbons within shale reservoirs during different geological stages. The abundant existence of organic matter within shales complicates the shale pore structure evolution process by hydrocarbon generation, migration and cracking. Many studies have been conducted to reveal the shale pore structure evolution characteristics and the controlling factors. Basically, these studies could be divided into two categories based on the sample source: comparing the pore structure of natural shale samples with different thermal maturities; obtaining shale samples with different thermal maturities by conducting thermal simulation experiments on low-mature shale samples and comparing the pore structure of these simulated shale samples. However, no consistent viewpoint on shale pore structure evolution has been reached. This review presents the state of the art of shale pore structure evolution studies. It is widely recognized in the literature that both the inorganic and organic diagenesis control the shale pore structure evolution process. However, it is found that the shale pore structure evolution models proposed in the literature were largely dependent on the samples used. And it is recommended to conduct the two categories of studies simultaneously in order to obtain more reliable shale pore structure evolution characteristics in future investigations.
\end{abstract}

\section{Introduction}

Shale hydrocarbons have been considered as one of the most promising unconventional petroleum resources since the economic production of shale gas in North America with the development of hydraulic fracturing and horizontal drilling technologies more than twenty years ago (Curtis, 2002). Many countries, such as United States, Canada and China, have made important breakthroughs in shale gas/oil exploration and the studies focusing on the unconventional petroleum geology and engineering are booming in recent years (e.g., Zhao et al., 2007; Ross and Bustin, 2008; Zou et al., 2010; Dai et al., 2014; Klaver et al., 2015; Pan et al., 2016; Wood and Hazra, 2018; Liu et al., 2019; Wood, 2019; Yang et al., 2020). Among these studies, reservoir characterization is regarded as one of the core research contents in unconventional petroleum geology (e.g., Loucks et al., 2009; Chalmers et al., 2012; Clarkson et al., 2013; Milliken et al., 2013). Organic-rich shales deposited in fine-grained sedimentary system usually underwent complicated diagenesis with the participation of organic fluids generated during the thermal evolution process of organic matter and finally oil/gas was distributed in pore spaces of shale reservoir either in free state, adsorbed state or dissolved state (Curtis, 2002; Ross and Bustin, 2007). Consequently, shale pore structure, which has experienced an intense and multi-stage transformation process and is more complicated than conventional reservoir rocks, has an important impact on hydrocarbon storage capability of shale reservoir (Ross and Bustin, 2009; Rexer et al., 2014).

In order to evaluate the reserve of shale hydrocarbons and predict the oil/gas production behavior accurately, it is quite meaningful to clarify the occurrence state of shale hydrocarbons and its controlling factors. Free gas/oil is easier to be

\section{Yandy} Scientific Press

${ }^{*}$ Corresponding author. E-mail address: gaozhiye@163.com (Z. Gao); 1037989355@qq.com (Y. Fan); 837209443@qq.com (Q. Xuan); 2586853207@qq.com (G. Zheng). 2207-9963 (c) The Author(s) 2020.

Received May 7, 2020; revised May 20, 2020; accepted May 20, 2020; available online June 2, 2020.
} 
produced without desorption process but adsorbed phase may provide huge amount of hydrocarbons in a long term if treated properly (Curtis, 2002). Shale pore structure is considered as one of the most important reservoir parameters controlling occurrence state of hydrocarbons (Curtis et al., 2010; Slatt and O'Brien, 2011; Chen and Xiao, 2014). Total pore volume and specific surface area are the two pore structure parameters determining the storage potential of free and adsorbed gas/oil in shale reservoirs respectively. Furthermore, the proportion and development characteristics of oil-wet organic matter $(\mathrm{OM})$ pores and water-wet inorganic pores also affect the occurrence state of hydrocarbons significantly. Consequently, many studies have been conducted to investigate the shale pore structure from qualitative description to quantitative characterization using advanced tools including high pressure mercury intrusion porosimetry (HPMIP), $\mathrm{N}_{2} / \mathrm{CO}_{2}$ adsorption, field emission-scanning electron microscopy (FE-SEM), focused ion beam-scanning electron microscopy (FIB-SEM), nuclear magnetic resonance (NMR), nanometer-computed tomography (Nano-CT) and small-angle scattering (Clarkson et al., 2012; Javadpour et al., 2012; Loucks et al., 2012; Kuila and Prasad, 2013; Milliken et al., 2013; Bahadur et al., 2015; Zhou and Kang, 2016; Gao and Hu, 2018). The widely used pore classification standard proposed by the International Union of Pure and Applied Chemistry (IUPAC) is that micropores $(<2$ $\mathrm{nm}$ ), mesopores $(2 \sim 50 \mathrm{~nm})$ and macropores $(>50 \mathrm{~nm}$ ) (Sing et al.,1985).

Total organic carbon (TOC) content, kerogen type, shale mineralogy and thermal maturity are generally considered as the main controlling factors of shale pore structure in the literature (e.g., Jarvie et al., 2007; Loucks et al., 2012; Mastalerz et al., 2013; Löhr et al., 2015). And it is quite meaningful to clarify how the shale pore structure changes with thermal maturity for understanding the evolution process of shale hydrocarbon occurrence state during different geological stages and the enrichment mechanism of shale hydrocarbons. However, it should be point out that most studies focused on the 'static' pore structure characterization and few studies were conducted to show a 'dynamic' pore structure evolution process. Furthermore, the limited studies focusing on shale pore structure evolution characteristics always showed different viewpoints on the function of $\mathrm{OM}$, brittle minerals, clay minerals and their interactions in shale pore structure evolution. Basically, the studies on shale pore structure evolution could be divided into two categories based on the sample source: (1) comparing the pore structure of natural shale samples with different thermal maturities; (2) obtaining shale samples with different thermal maturities by conducting thermal simulation experiments on low-mature shale samples and comparing the pore structure of these simulated shale samples. This review presents the state of the art of shale pore structure evolution studies in these two categories.

\section{Natural shale samples with different thermal maturities}

Jarvie et al. (2007) found a porosity increase with increasing thermal maturity when they conducted a thermogenic shale-gas assessment study on the Mississippian Barnett Shale of north-central Texas and attributed this phenomenon to the thermal conversion of kerogen to petroleum but no further investigation was conducted on shale pore structure evolution.

Based on the collected data of mudrocks from 26 geologic units (from Cambrian to Pliocene-Pleistocene), Loucks et al. (2012) classified the pores in mudrocks into three types including interparticle and intraparticle pores associated with mineral particles as well as OM pores and they described the pore structure characteristics of each type and discussed their origins in details. Furthermore, they presented a preliminary discussion on the evolution of mudrock pores with time and burial. Mechanical compaction, which causes a great loss of interparticle and intraparticle pores, is the most important process during the early history of burial with limited carbonate, phosphate, and early pyrite diagenesis (Raiswell, 1976; Föllmi, 1996; Wilkin et al., 1996, 1997). With the increase of burial depth and temperature (e.g., $>100{ }^{\circ} \mathrm{C}$ ), the transformation of smetite to illite occurs commonly and the pore space could be filled with the new authigenic clays and minerals formed using the released elements (e.g., silica, calcium and so on) from this transformation process (Freed and Peacor, 1989; Pearce et al., 1991; Hatch, 2012). In the burial temperature range of $80-120{ }^{\circ} \mathrm{C}$, dissolved pores could be produced by the dissolution of unstable carbonates and feldspars, which is caused by the carboxylic and phenolic acids generated from the decarboxylation of kerogen. Loucks et al. (2012) also pointed out OM pores began to form with the start of organic thermal maturation but no linear correlation between OM pore development and increased maturation was observed in Barnett Shale samples covering a range of vitrinite reflectance $\left(R_{0}\right)$ values $(0.5 \% \sim 3.17 \%)$. Basically, Loucks et al. (2012) mentioned most of the diagenesis processes involved in the pore structure evolution of shale samples and briefly showed the development situation of three pore types in different diagenetic stages. However, the main objective of their study was not clarifying the pore structure evolution process of shale samples and no specific pore structure evolution model was established by Loucks et al. (2012).

Considering the significant impact of $\mathrm{OM}$ pores on the storage and production of shale hydrocarbons, Curtis et al. (2012) conducted a tentative investigation on the development of organic porosity with increasing thermal maturity using eight Woodford Shale samples from Oklahoma in USA with a mixture of type II and III kerogen and $\mathrm{R}_{\mathrm{o}}$ values ranging from $0.51 \%$ to $6.36 \%$. By setting thresholds on the gray scale of SEM images, they obtained the OM content and organic porosity of each sample. It was found OM content in the milled sample areas decreased with the increase of thermal maturity, which was possibly due to the limited observation area in each SEM image or thermal alteration and compaction of OM. However, no systematic evolution trend was observed in the organic porosity with increasing thermal maturity. More specifically, no OM pores were found in shale samples with $0.9 \% \mathrm{R}_{\mathrm{o}}$ and below while OM pores were quite well-developed in shale samples with $1.23 \% \mathrm{R}_{\mathrm{o}}$ and above (except $2.0 \% \mathrm{R}_{\mathrm{o}}$ sample). Furthermore, based on the observation of no organic porosity in $2.0 \% \mathrm{R}_{\mathrm{o}}$ sample and the co-existence of porous 
and non-porous $\mathrm{OM}$ within less than a micron domain in $1.4 \% \mathrm{R}_{\mathrm{o}}$ sample, they concluded thermal maturity was not the only factor controlling the development of OM pores and other factors such as organic matter composition should also be considered. It should be noted that the mineral compositions of these eight Woodford Shale samples were not provided and their possible effects on the OM pore structure evolution were not discussed by Curtis et al. (2012).

Milliken et al. (2013) investigated the OM pores developed in Marcellus Formation samples from two wells with different thermal maturities $\left(\sim 1.0 \% \mathrm{R}_{\mathrm{o}}\right.$ and $\sim 2.1 \% \mathrm{R}_{\mathrm{o}}$ respectively $)$ in northern Pennsylvania. One of their main findings was the controlling effect of total organic carbon (TOC) not thermal maturity on the development of $\mathrm{OM}$ pores, which was inconsistent with previous studies. After plotting porosity versus TOC, samples from each well exhibited a linear trend line and these two trend lines showed different intersections but similar slopes, which indicated the controlling effect of TOC on porosity and the similar OM porosity developed in these samples with two different thermal maturities. More specifically, they found a positive correlation between TOC and porosity for samples with TOC less than $5.5 \mathrm{wt} \%$ while this positive correlation vanished in samples with higher TOC. Furthermore, visible OM porosity under FE-SEM decreased with increasing TOC and the morphology and OM pore size also showed systematic variations with TOC. As to the causing mechanism of this 'surprising' result, they postulated that higher TOC might have greater OM connectivity and generate a more effective pathway for gas expulsion leading to the compaction of shale matrix and squeezing of OM pores. Milliken et al. (2013) pointed out OM type difference between samples with higher and lower TOC could also cause their different OM pore structures. However, the significant impact of thermal maturity on shale pore structure evolution could not be excluded considering the samples with only two different thermal maturities used by Milliken et al. (2013).

In order to clarify shale pore structure evolution process with increasing thermal maturity, a systematic shale pore structure characterization of Devonian and Mississippian New Albany Shale samples with marine type II kerogen and a $\mathrm{R}_{\mathrm{o}}$ value range from $0.35 \%$ to $1.41 \%$ was conducted by Mastalerz et al. (2013). Low-pressure gas $\left(\mathrm{N}_{2}\right.$ and $\left.\mathrm{CO}_{2}\right)$ adsorption, mercury intrusion porosimetry (MIP) and helium porosimetry(HP) were conducted to quantitatively characterize the whole-aperture pore size distribution of shale samples. As mentioned by Mastalerz et al. (2013), the well-documented coal-specific knowledge about the pore structure evolution of macerals with increasing coal rank was probably insufficient to reveal shale pore structure evolution process due to the possible and unique impacts of hydrocarbon generation, cracking, and formation of solid bitumen on pore structure in shale samples (Jarvie et al., 2007; Loucks et al., 2009; Curtis et al., 2011), which also confirmed the significance of Mastalerz et al. (2013)'s work. The results of organic petrography analysis showed different TOC contents and compositions of these samples. The distribution characteristics of $\mathrm{OM}$ and pores larger than $1 \mu \mathrm{m}$ observed under reflected light microscopy showed considerable differences among these samples with different thermal maturities and the interconnection of $\mathrm{OM}$ network seemed to be optimized gradually with the increase of thermal maturity. A nonlinear and trough-shaped trend between total pore volume and thermal maturity was indicated by both HP and MIP results and late mature sample IL-5 $\left(1.15 \% \mathrm{R}_{\mathrm{o}}\right)$ had the lowest pore volume. More specifically, the changing tendency of micropores, mesopores and macropores with increasing thermal maturity was discussed separately by Mastalerz et al. (2013). The micropore volume and mesopore volume were quantified by $\mathrm{CO}_{2}$ adsorption and $\mathrm{N}_{2}$ adsorption respectively while the macropore volume was obtained by subtracting micropore volume and mesopore volume from HP total pore volume. Both the micropore volume and mesopore volume decreased first with increasing thermal maturity to a minimum in sample IL-5 $\left(1.15 \% \mathrm{R}_{\mathrm{o}}\right)$ and then increased again for sample IL-1 $\left(1.41 \% \mathrm{R}_{\mathrm{o}}\right)$ while this trend was not obvious for macropores. Furthermore, the BET surface area derived from $\mathrm{N}_{2}$ adsorption, average micropore size derived from $\mathrm{CO}_{2}$ adsorption, total pore area and median pore-throat diameter obtained from MIP all reached a minimum in sample IL-5 $\left(1.15 \% \mathrm{R}_{\mathrm{o}}\right)$. Different from the viewpoint of Milliken et al. (2013), no obvious correlation between the total pore volume and TOC was observed by Mastalerz et al. (2013), which may be masked by the strong differences in thermal maturity. The lack of correlation between pore volume and TOC may also indicate the significant contributions of both interparticle pores and intraparticle pores to the pore spaces of these samples. In addition, Mastalerz et al. (2013) also pointed out the influences of different minerals on porosity were masked by the strong influence of thermal maturity and the micropore volume was mainly provided by $\mathrm{OM}$ and clay minerals. Finally, a systematic and classic shale pore structure evolution model with 4 stages was proposed by Mastalerz et al. (2013). Stage I $\left(\mathrm{R}_{\mathrm{o}}<0.55 \%\right)$ : the total pore volume decreased a lot with the increase of thermal maturity due to the strong compaction. Stage II $\left(0.55 \%<\mathrm{R}_{0}<0.65 \%\right)$ : the total pore volume increased a little with the increase of thermal maturity due to the primary cracking of OM. Stage III $\left(0.65 \%<\mathrm{R}_{0}<1.15 \%\right)$ : the total pore volume decreased again with the increase of thermal maturity due to the oil filling and solid bitumen formation, which was approved by the significant pore volume increase of sample IL-5 $\left(1.15 \% \mathrm{R}_{\mathrm{o}}\right)$ after dichloromethane extraction. Stage IV $\left(\mathrm{R}_{\mathrm{o}}>1.15\right)$ : the total pore volume increased again with the increase of thermal maturity due to the secondary cracking of OM. However, the monotonous increasing trend of pore volume after $R_{0}>1.15$ was probably not the case and the thermal maturity values at which the changing tendency of the pore volume reversed were disputable (Liu et al., 2017). Although this model was not perfect and more relevant studies were required to improve it, Mastalerz et al. (2013) indeed presented a representative methodology of investigating shale pore structure and its evolution process

The OM pore structure evolution characteristics of overmature shales were discussed by Wang et al. (2013). For shale samples with comparable TOC content $(2 \% \sim 3 \%)$, the Lower Cambrian Qiongzhusi Formation shale samples with higher thermal maturity $(2.5 \% \sim 2.8 \%$ equivalent vitrinite reflectance $\mathrm{R}_{\text {equ }}$ ) had lower porosities (2\% 3\%) compared with the 
Upper Ordovician-Lower Silurian Longmaxi Formation shale samples with $2.0 \% \sim 2.3 \% \mathrm{R}_{\text {equ }}$ and 5\% 7\% porosity, both of which were collected from the Sichuan Basin in China. Consequently, Wang et al. (2013) pointed out the increasing trend of $\mathrm{OM}$ porosity with increasing thermal maturity ceased at $2.0 \% \mathrm{R}_{\mathrm{o}}$ and the $\mathrm{OM}$ porosity began to decline when thermal maturity was above $2.0 \% \mathrm{R}_{\mathrm{o}}$. Furthermore, the preservation conditions of pore spaces also significantly controlled the development of OM porosity. Wang et al. (2013) also pointed out the matrix porosity of shale continued to decrease with increasing thermal maturity.

Focusing on the structure of OM in Barnett Shale samples with a series of thermal maturities from immature to wet-gas stage, Sarmiento et al. (2014) used $\mathrm{N}_{2}$ adsorption method and high resolution transmission electronic microscopy (HRTEM) to characterize the pore volume and nanostructure of isolated kerogens respectively. The results of $\mathrm{N}_{2}$ adsorption showed that both the mesopore volume and BET surface area of isolated kerogens from different Barnett shale samples increased with increasing thermal maturity. The HRTEM images directly showed the existence of micropores and mesopores in these isolated kerogens. In immature isolated kerogens with a quasiamorphous structure, micropores were considered to result from the quasi-random orientation of aromatic layers $(<1$ $\mathrm{nm})$. In gas-mature isolated kerogens, mesopores $(2-50 \mathrm{~nm})$ resulted from the disorientation of abundant basic structural units formed by stacking of larger aromatic layers $(>1 \mathrm{~nm})$ and the disorientation of molecular orientation domains formed by parallel arrangement of the basic structural units. Furthermore, the carbon nanoparticles of concentric nanostructure were observed within gas-mature samples by HRTEM and were possibly generated by secondary cracking of hydrocarbons (Alfe et al., 2009). However, no specific OM pore structure evolution model was established by Sarmiento et al. (2014).

The evolution of porosity and pore types in Lower Toarcian Posidonia Shale samples from the Lower Saxony Basin in North Germany was characterized by Mathia et al. (2016). A total of 26 samples with a $R_{o}$ value range of $0.53 \% \sim 1.45 \%$ were used and these samples mainly consisted of microfossiferous calcite, clay minerals and type II OM. The porosities of immature samples, oil-windows samples and gas-window samples were $10 \% \sim 14 \%, 3 \% \sim 5 \%$ and $9 \% \sim 12 \%$ respectively and the evolution of porosity was generally following the model proposed by Mastalerz et al. (2013). The shale compositions, carbonate diagenesis, compaction and thermal evolution of organic phases were considered to be the main controlling factors of porosity changes at different thermal maturities. Furthermore, the heterogeneity of OM porosity was confirmed by the wide macroporosity range $(0 \sim 40 \%)$ of different individual organic particles and the fact that no macropores were developed in $65 \%$ of the total organic particles. The physicochemical differences among different organic particles and the different mechanical protection provided by the mineral matrix could lead to the heterogeneity of OM porosity. However, most of the mesopores and all of the micropores could not be quantified due to the limited resolution (pixel size $15 \mathrm{~nm}$ ) of SEM used by Mathia et al. (2016) and no complementary methods (e.g., gas adsorption and MIP) were conducted to quantitatively characterize the micropores and mesopores, which restricted the acquisition of accurate and complete shale pore structure evolution information to some extent.

Liu et al. (2017) qualitatively and quantitatively characterized the pore structure of Longmaxi Formation shale samples from the Sichuan Baisn in China and proposed a double-pore evolution conceptual model which included both the evolution characteristics of inorganic pores and organic pores based on their own data and the data from previous studies (e.g., Curtis et al., 2012; Wang et al., 2013). This model was different from the aforementioned models and was divided into 5 stages: (1) immature stage with rapid compaction $\left(\mathrm{R}_{\mathrm{o}}<0.7 \%\right)$ : inorganic pores were reduced rapidly by compaction while no significant change occurred for organic pores. (2) mature stage with hydrocarbon generation-dissolution $\left(0.7 \%<\mathrm{R}_{\mathrm{o}}<1.3 \%\right)$ : secondary inorganic porosity was increased by dissolution of carbonates and feldspar with the participation of organic acids and organic porosity was also increased by formation of OM pores during hydrocarbon generation. (3) high-mature stage with pore filling $\left(1.3 \%<\mathrm{R}_{0}<2.2 \%\right)$ : inorganic pores were decreased slowly by compaction and organic porosity was declined by the OM pore filling of bitumen. (4) overmature stage with secondary cracking $\left(2.2 \%<\mathrm{R}_{0}<2.7 \%\right)$ : inorganic porosity continued to decrease slowly by compaction while organic porosity was increased due to the secondary cracking of OM. (5) overmature stage with slow compaction $\left(\mathrm{R}_{\mathrm{o}}>2.7 \%\right)$ : both the organic and inorganic porosities were reduced slowly by compaction. The correlations between shale porosity and TOC observed by Milliken et al. (2013) were partially supported by Liu et al. (2017), which indicated the important and complicated influence of TOC on shale porosity.

The influence of thermal maturity on shale pore structure was also confirmed by Dong et al. (2019) by using Upper Devonian Duvernay Formation shale samples with a thermal maturity range from immature to dry-gas window from Western Canada Sedimentary Basin. The TOC ranged from 0.1 to $11.3 \mathrm{wt} \%$ and the crossplots of HI versus $T_{\max }$ indicated the dominant type II OM with a minor contribution of type III terrigeneous $\mathrm{OM}$ in these shale samples. $\mathrm{N}_{2}$ adsorption and MIP were used to quantitatively characterize shale pore structure while FE-SEM and helium ion microscopy (HIM) were applied to qualitatively characterize shale pore structure. As mentioned by Wang et al. (2016), HIM had a higher resolution and better imaging results than SEM, which was also confirmed by Dong et al. (2019). The correlations between pore structure (permeability, porosity, pore volume of microopre, mesopore and macropore) and shale compositions (TOC and $\mathrm{SiO}_{2}, \mathrm{Al}_{2} \mathrm{O}_{3}, \mathrm{CaO}$ ) were investigated in detail. The results showed a positive correlation between porosity and quartz content, a negative correlation between porosity and carbonate content and a weakly positive correlation between permeability and $\mathrm{SiO}_{2}$ content. And samples with higher thermal maturity tended to have a smaller pore size. Dong et al. (2019) divided the shale pore structure evolution process into three stages based on their samples: (1) from immature to oil window: porosity decreased due to compaction. (2) from oil window to wet-gas window: the formation of secondary OM pores 
The volume of different types of pores

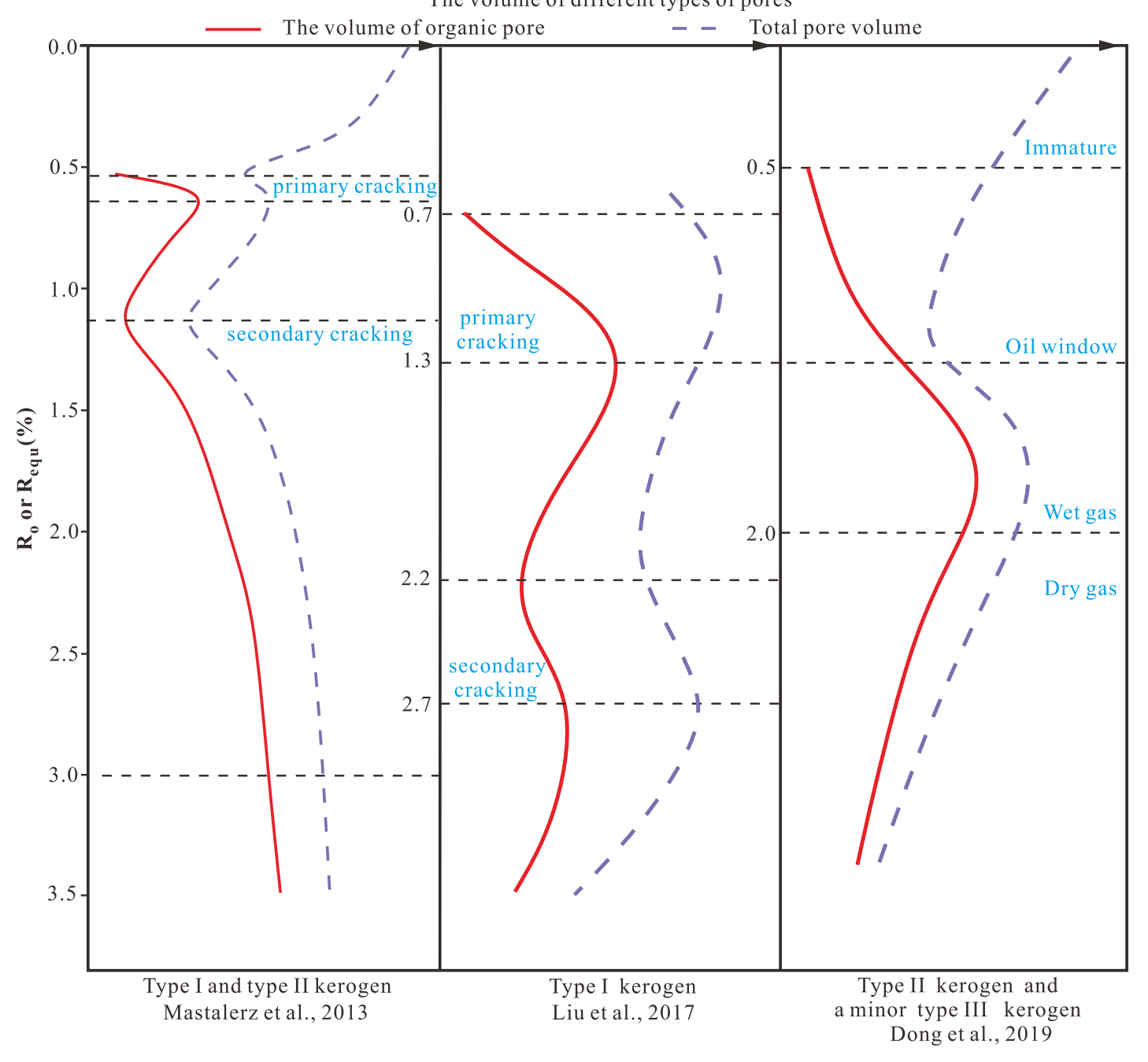

Fig. 1. Pore structure evolution models proposed by different scholars using natural shale samples with different thermal maturities.

and feldspar dissolution pores, the primary pore preservation by the quartz framework caused the increase of porosity. The critical role of silica nanospheres and microcrystalline quartz on pore preservation was further approved by Dong and Harris (2020). (3) from wet-gas window to dry-gas window: the OM pores and dissolution pores were compacted leading to the porosity decrease. Furthermore, Dong et al. (2019) pointed out the changes of pore type in shale samples with different thermal maturities. The dominant pores developed in immature samples were interparticle pores between clay minerals and other mineral grains while OM fissures were widely distributed in oil-window samples and secondary bubble-like OM pores were well developed in gas-window samples. It could be seen that this shale pore structure evolution model was somewhat different from the previous models proposed by Mastalerz et al. (2013) and Liu et al. (2017), which was closely related to the different shale samples used by these scholars.

By conducting a thorough literature review of shale wettability characterization using spontaneous imbibition experiments, Gao et al. (2019) established a wettability evolution model considering the significant impact of pore structure on shale wettability. This model was divided into four stages: (1) $0.5 \%<\mathrm{R}_{\mathrm{o}}<1.3 \%$ : OM pores began to form by primary cracking of $\mathrm{OM}$ while inorganic pores were reduced by compaction and oil filling. However, inorganic pores were still the dominant pore type at this stage. (2) $1.3 \%<\mathrm{R}_{\mathrm{o}}<2.0 \%$ : many $\mathrm{OM}$ pores were generated by secondary cracking of OM while inorganic pores were further eliminated due to the enhanced compaction. The comparative relationship between inorganic pores and OM pores was not fixed at this stage. (3) $2.0 \%<\mathrm{R}_{\mathrm{o}}<3.0 \%$ : OM pores became the dominant pore type due to the secondary cracking of $\mathrm{OM}$ and the massive elimination of inorganic pores by strong compaction. (4) $\mathrm{R}_{\mathrm{o}}>3.0 \%$ : $\mathrm{OM}$ pores were reduced due to the weakened secondary cracking of $\mathrm{OM}$ and strong compaction. It should be noted that this model was empirical and simplified, which required a lot of further studies to verify its validity.

In summary, the abovementioned studies always showed different shale pore structure evolution models (Fig. 1; Table 1), which indicated the strong dependence of these models on used shale samples and the difficulty of obtaining a unified shale pore structure evolution model. However, the controlling 
Table 1. The shale pore structure evolution stages and controlling factors indicated from natural shale samples with different thermal maturities in the literature.

\begin{tabular}{|c|c|c|c|c|c|}
\hline Formation name & Stage & $\mathrm{R}_{\mathrm{o}}(\%)$ & Pore evolution* & Main factors & Reference \\
\hline \multirow{4}{*}{$\begin{array}{l}\text { Devonian and } \\
\text { Mississippian }\end{array}$} & stage 1 & $<0.55 \%$ & Decreased a lot & compaction & \multirow{4}{*}{ Mastalerz et al., 2013} \\
\hline & stage 2 & $0.55 \% \sim 0.65 \%$ & Increased a little & primary cracking of $\mathrm{OM}$ & \\
\hline & stage 3 & $0.65 \% \sim 1.15 \%$ & Decreased & oil filling and bitumen formation & \\
\hline & stage 4 & $>1.15 \%$ & Increased & secondary cracking of OM & \\
\hline \multirow{5}{*}{ Longmaxi } & stage 1 & $<0.7 \%$ & IP decreased rapidly & compaction & \multirow{5}{*}{ Liu et al., 2017} \\
\hline & stage 2 & $0.7 \% \sim 1.3 \%$ & IP and OP increased & $\begin{array}{l}\text { hydrocarbon generation and disso- } \\
\text { lution }\end{array}$ & \\
\hline & stage 3 & $1.3 \% \sim 2.2 \%$ & IP and OP decreased & compaction and bitumen filling & \\
\hline & stage 4 & $2.2 \% \sim 2.7 \%$ & IP decreased OP increased & $\begin{array}{l}\text { compaction and secondary crack- } \\
\text { ing of OM }\end{array}$ & \\
\hline & stage 5 & $>2.7 \%$ & Decreased slowly & compaction & \\
\hline \multirow{3}{*}{ Duvernay } & $\begin{array}{l}\text { immature-oil } \\
\text { window }\end{array}$ & $0.5 \% \sim 1.3 \%$ & Total porosity decreased & compaction & \multirow{3}{*}{ Dong et al., 2019} \\
\hline & $\begin{array}{l}\text { oil window-wet- } \\
\text { gas window }\end{array}$ & $1.3 \% \sim 2.0 \%$ & $\begin{array}{l}\text { Micropore and total } \\
\text { porosity increased }\end{array}$ & $\begin{array}{l}\text { hydrocarbon generation and disso- } \\
\text { lution }\end{array}$ & \\
\hline & $\begin{array}{l}\text { wet-gas window- } \\
\text { dry-gas window }\end{array}$ & $>2.0 \%$ & Decreased & compaction & \\
\hline
\end{tabular}

*IP=Inorganic porosity, OP=Organic porosity

effects of inorganic and organic diagenesis on shale pore structure evolution are widely recognized in the literature.

\section{Shale samples with different thermal maturities from thermal simulation experiments}

Following the time-temperature compensation principle proposed by Connan (1974), thermal simulation experiments conducted at a consecutive series of high temperatures are considered as a practical method to simulate the long-time low-temperature geological evolution process in a relatively short experimental time. In recent years more and more studies are conducted to reveal the shale pore structure evolution process using thermal simulation experiments.

Anhydrous pyrolysis experiments were conducted on three low maturity shales/mudstones with $\sim 0.60 \% \mathrm{R}_{\mathrm{o}}$ and a coal sample with $0.56 \% \mathrm{R}_{\mathrm{o}}$ by Chen and Xiao (2014). Two organicrich shale samples LCG and DL were collected from an Upper Permian outcrop (Yaomoshan, Urumqi) of the southern Junggar Basin and an Upper Permian outcrop (Changjianggou, Guangyuan) in the northern Sichuan Basin respectively. The organic-lean mudstone sample EP from an Oligocene deposit of well WC19-1M-1 in the western Pearl River Mouth Basin was used to investigate the pore structure evolution characteristics of clay minerals. The purpose of conducting pyrolysis experiment on the coal sample with a similar initial thermal maturity was to indicate the thermal maturity of the shale samples at different pyrolysis temperatures by measuring the thermal maturity of the coal sample at the equivalent pyrolysis temperatures (Waples, 1980; Sweeney and Burnham, 1990). The anhydrous pyrolysis experiments were conducted at temperatures from 300 to $750{ }^{\circ} \mathrm{C}$ with $50{ }^{\circ} \mathrm{C}$ intervals to obtain a series of simulated samples with a $R_{o}$ value range from $0.69 \%$ to $4.19 \%$. Low-pressure $\mathrm{N}_{2}$ adsorption tests and $\mathrm{CO}_{2}$ adsorption tests were applied to quantitatively characterize the mesopores and micropores in simulated samples respectively. Samples LCG and DL generally showed similar pore structure evolution characteristics in the whole maturity range with just a little difference occurring in the oil window: the specific surface area and volume of micropores and mesopores for sample LCG arrived at a minimum around the oil window $\left(\mathrm{R}_{\mathrm{o}}=0.89 \%\right)$ while these parameters of sample DL showed a slight increase in this thermal maturity range. Furthermore, Chen and Xiao (2014) attributed this difference to the oil generation potential difference between these two samples. More specifically, sample LCG had oil-prone kerogen which could produce a lot of asphaltene-rich bitumen causing obvious pore filling and porosity decrease in the oil window stage while sample DL contained gas-prone kerogen which could only generate a small amount of bitumen showing little influence on shale pore structure. However, the surface areas and volumes of micropores and mesopores for sample EP showed a monotonous decreasing trend with increasing thermal maturity due to the dehydration and framework collapse of clay minerals during thermal maturation process. Chen and Xiao (2014) pointed out the opposite tendency of pore structure evolution between OM and clay minerals determined the shale pore structure evolution characteristics. Finally, Chen and Xiao (2014) proposed an OM pore structure evolution model which could be divided into three stages: (1) formation stage of OM-hosted nanopores $\left(0.6 \%<\mathrm{R}_{0}<2.0 \%\right)$ : OM pores were produced by oil generation and thermal cracking of generated oil. The residual oil rich in asphaltene and resin formed with the migration of generated oil could cause the 
pore filling and porosity decrease in oil-prone shales within the oil window stage. The nanoporous pyrobitumen produced by oil cracking to gaseous hydrocarbons at higher thermal maturity and residue kerogen made a contribution to the total pore spaces. (2) developing stage of OM-hosted nanopores $\left(2.0 \%<\mathrm{R}_{\mathrm{o}}<3.5 \%\right)$ : OMs with a graphitic-like structure and a large number of nanopores were produced by further thermal cracking of kerogen and pyrobitumen and the secondary cracking of heavy hydrocarbon gases, which caused a rapid increase of pore volume and specific surface area of micropores and mesopores. (3) conversion and destruction stage of OM-hosted nanopores $\left(\mathrm{R}_{0}>3.5 \%\right)$ : the transformation of micropores to mespores and/or mesopores to macropores was indicated by the decrease of mircoporosity and the increase of mesoporosity under the experimental conditions at this stage. However, OM pores could be compacted under geological conditions. It should be noted that direct FE-SEM observations of shale pore structure and analysis of gaseous products during pyrolysis experiments were not performed by Chen and Xiao (2014). There was no external pressure and no water (or brine) during the pyrolysis experiments, which could not accurately represent the actual geological conditions. Consequently, all these issues impaired the reliability of the OM pore structure evolution model proposed by Chen and Xiao (2014).

Hydrous pyrolysis experiments with controlled lithostatic pressure $(100 \mathrm{MPa})$ and hydrodynamic pressure $(50 \mathrm{MPa})$ were conducted by Sun et al. (2015) using a Triassic Yanchang Formation Chang 7 member oil-shale sample with type I kerogen, a TOC of $13.75 \%$ and $0.7 \% \mathrm{R}_{\mathrm{o}}$ from an outcrop in Ordos Basin of China. The pyrolysis experiments were conducted at temperatures of $250{ }^{\circ} \mathrm{C}, 300{ }^{\circ} \mathrm{C}, 350{ }^{\circ} \mathrm{C}, 375$ ${ }^{\circ} \mathrm{C}, 400{ }^{\circ} \mathrm{C}, 450{ }^{\circ} \mathrm{C}$ and $500{ }^{\circ} \mathrm{C}$. The expelled oil, washout oil, residue oil and generated gas were collected and measured once the experiment was completed. $\mathrm{N}_{2}$ adsorption was the only pore structure characterization method used by Sun et al. (2015). The total pore volume, surface area as well as the pore volume and specific surface area of micropores, mesopores and macropores showed an increasing tendency with increasing temperature. In addition, the average pore diameters of macropores and mesopores decreased with increasing temperature. The pore structure evolution process was divided into three stages by Sun et al. (2015): (1) 250 300 ${ }^{\circ} \mathrm{C}$ : primary pores were filled by generated hydrocarbons. (2) $350 \sim 375{ }^{\circ} \mathrm{C}$ : secondary pores were produced by hydrocarbon generation. (3) $400 \sim 500{ }^{\circ} \mathrm{C}$ : more secondary pores were generated because of thermal cracking of generated oil. It should be noted that the pyrolysis experiments conducted by Sun et al. (2015) were already optimized to reflect the actual geological conditions. However, lacking of direct FE-SEM observations of shale pore structure and the solely application of $\mathrm{N}_{2}$ adsorption tests to obtain pore structure were the main issues existed in the work of Sun et al. (2015).

Wu et al. (2015) also conducted thermal simulation experiments with high temperature and pressure $(90 \mathrm{MPa})$ on low mature Triassic Yanchang Formation Chang 7 Member shale samples $\left(2452.6 \mathrm{~m}\right.$ depth, $0.67 \% \mathrm{R}_{0}$, a TOC of $2.23 \%$ and type II kerogen) from the Ordos Basin. The thermal simulation experiments were conducted at three temperature points of
$350{ }^{\circ} \mathrm{C}, 450{ }^{\circ} \mathrm{C}, 550{ }^{\circ} \mathrm{C}$ and the corresponding values of $\mathrm{R}_{\mathrm{o}}$ were $1.0 \% \sim 1.5 \%, 2.0 \% \sim 2.5 \%, 2.5 \% \sim 3.0 \%$ respectively. Compared with Sun et al. (2015), Wu et al. (2015) realized the direct 'in-situ' observations of shale pore structure evolution by repeatedly conducting Nano-CT or FE-SEM tests on the same sample block which went through all the three temperature points, and provided a possible way to observe shale pore structure evolution directly. Nano-CT results showed the pore-throat size and development level of pores in simulated samples increased rapidly from 350 to $450{ }^{\circ} \mathrm{C}$ and increased slowly from 450 to $550{ }^{\circ} \mathrm{C}$. The $\mathrm{N}_{2}$ adsorption results showed an increase trend of BET surface area and pore volume of simulated samples with increasing temperature. Based on their observations, Wu et al. (2015) pointed out thermal evolution of OM made the greatest contribution to shale pore structure evolution, followed by the transformation of clay minerals and the evolution of brittle minerals made the least contribution. The OMs developed in Chang 7 member shale sample were categorized into two types according to their morphology (OM with irregular shapes and microfractures and OM with block shapes and no microfractures) and these two types of OM generally showed similar evolution tendency. As the increase of simulation temperature, OMs were thermally cracked to generate hydrocarbons with the formation of OM pores and finally OMs were completely cracked and evolved into large pores. These two types of OM also showed a little evolution difference. OM with microfractrues generated pore spaces mainly in two forms: the extension of microfrctures within OM and the formation of microfractures at the interface between $\mathrm{OM}$ and mineral matrix. The pores developed in OM with block shapes were mainly distributed at the interface between $\mathrm{OM}$ and mineral matrix due to the shrinkage of OM. With the increase of simulation temperature, the intra-particle pores were gradually generated in I/S mixed layer clay minerals and chlorite. The pore size of intra-particle pores developed in clay minerals increased significantly at $350{ }^{\circ} \mathrm{C}$ and did not change a lot after this temperature, which indicated the contribution of transformation of clay minerals to pore spaces was quite limited after the gas-window. The dissolution pores generated by the interaction between unstable minerals (feldspar and calcite) and organic fluids were also observed but their pore size and pore connectivity were not significantly increased with increasing temperature. Finally, Wu et al. (2015) proposed a shale pore structure evolution model which was divided into three stages: (1) $R_{0}<0.5$ : the pore system was reduced rapidly due to the mechanical compaction. (2) $350 \sim 450{ }^{\circ} \mathrm{C}$ : the pore system was increased rapidly due to the formation of $\mathrm{OM}$ pores, dissolution pores and intra-particle pores developed in clay minerals. (3) $550{ }^{\circ} \mathrm{C}$ : the pore system was kept stable at this stage due to the weak thermal cracking of OM, the enhanced stability of shale framework and the stable fluid environment. Furthermore, Wu et al. (2019) expanded their study to marine Proterozoic Xiamaling Formation shale sample in the North China Platform $\left(\mathrm{R}_{\mathrm{o}}<0.7 \%\right.$, TOC $>2.2 \%$, and type II kerogen) and lacustrine Permian Lucaogou Formation shale sample in the Junggar Basin $\left(\mathrm{R}_{0}<0.7 \%\right.$, TOC $>2.2 \%$, and type II kerogen) using similar experimental procedures with $\mathrm{Wu}$ et al. (2015). Basically, the results of Wu et al. 
(2019) were consistent with those of $\mathrm{Wu}$ et al. (2015). One of the main progresses made by $\mathrm{Wu}$ et al. (2019) was that an improved shale pore structure evolution model with four stages was proposed by adding a new stage $\left(250 \sim 300{ }^{\circ} \mathrm{C}\right)$ to the model proposed by Wu et al. (2015). During the stage of $250 \sim 300{ }^{\circ} \mathrm{C}$, inorganic pores were further reduced due to the mechanical compaction while organic pores were increased first due to the pyrolysis of $\mathrm{OM}$ and then decreased by the swelling of OM caused by the adsorption and dissolution of generated liquid hydrocarbons in the kerogen framework. It could be seen that the model proposed by Wu et al. (2019) did not show a decreasing trend of porosity during the overmature stage and the highest temperature of $550{ }^{\circ} \mathrm{C}$ used by $\mathrm{Wu}$ et al. (2015) and Wu et al. (2019) was possibly not high enough to reveal a complete shale pore structure evolution process.

Ko et al. (2016) conducted anhydrous gold tube pyrolysis experiments under confining pressure $(68.95 \mathrm{MPa})$ on lowmaturity Upper Cretaceous Boquillas Formation (Eagle Fordequivalent) organic-lean calcareous mudrock samples $(\sim 0.7 \%$ $\mathrm{R}_{\mathrm{O}}$ and type II kerogen) from outcrops along US Highway 90, west of Del Rio, Texas. The pyrolysis experiments were conducted at seven temperature points: $130{ }^{\circ} \mathrm{C}, 300{ }^{\circ} \mathrm{C}$, $310{ }^{\circ} \mathrm{C}, 333{ }^{\circ} \mathrm{C}, 367{ }^{\circ} \mathrm{C}, 400{ }^{\circ} \mathrm{C}, 425{ }^{\circ} \mathrm{C}$. The shale pore structure evolution characteristics were mainly investigated by geochemical analysis and SEM petrography. Ko et al. (2016) provided the definitions of four different OM pore types categorized by their morphology and origin: primary OM pores, convoluted OM pores, spongy OM pores and shrinkage OM pores. The generation of spongy OM pores was related to the thermal maturation of OM. Primary OM pores were inherited from original $\mathrm{OM}$ and convoluted $\mathrm{OM}$ pores were produced due to the deformation of $\mathrm{OM}$, both of which were not related to the thermal maturation of OM. The shrinkage OM pores were considered as artifacts formed due to the postexperimental temperature and confining pressure drops. The modified mineral pores with relic OM proposed by Ko et al. (2016) were related to petroleum migration in shale. Ko et al. (2016) also provided the working definitions of OM, kerogen, bitumen, solid (or solidified) bitumen, pyrobitumen, char and residual (or retained) oil in their study. Basically, Ko et al. (2016) divided the shale pore structure evolution process into three stages: Stage I (Bitumen generation; $130 \sim 310{ }^{\circ} \mathrm{C}$ ): modified mineral pores were the dominant pore type in this stage. Stage II (Early oil and oil window; 333 367 ${ }^{\circ} \mathrm{C}$ ): the spongy OM pores were generated in this stage but the modified mineral pores with isopachous OM rim were still the dominant pore type. Stage III (peak oil generation and cracking of oil to gas; $400 \sim 425{ }^{\circ} \mathrm{C}$ ): the modified mineral pores and nanometer-sized spongy $\mathrm{OM}$ pores were the two dominant pore types in this stage. Furthermore, Ko et al. (2016) also evaluated the pore structure of four different types of matrix and the development level of porosity and pore size was in the following order: calcite-dominated matrix $>$ mixed matrix (clay mineral, calcite and quartz) $>$ quartzdominated matrix $>$ clay mineral-dominated matrix. The pore size distribution of different types of matrix was influenced by grain size (Dewhurst et al., 1998, 1999) and could affect the evolution process of mineral pores and OM pores. The overall porosity in the calcite-dominated matrix was lower in the early oil cracking to gas stage compared with bitumen and oil generation stage while the overall porosity in all the other three types of matrix showed an increasing trend with increased thermal maturation. Consequently, depositional and diagenetic (physical compaction and chemical alteration) processes and thermal maturation of $\mathrm{OM}$ were considered as the controlling factors of shale pore structure evolution. In addition, Ko et al. (2016) made a pore structure comparison between naturally matured Eagle Ford core samples with calcite-dominated facies and artificially heated Boquillas samples. The main difference was the abundant existence of modified mineral pores in the artificially heated early gas window samples, which was possibly caused by their different mechanisms of petroleum retention. Following the work of Ko et al. (2016), Ko et al. (2018) expanded their investigations of shale pore structure evolution to Upper Devonian-Lower Mississippian Woodford and Mississippian Barnett immature mudstones. Barnett siliceous mudstone with dominant type II kerogen showed similar pore structure evolution characteristics to that proposed by Ko et al. (2016) for Boquillas Formation (Eagle Ford-equivalent) mudstones while Woodford siliceous mudstone with dominant type II kerogen had a different pore evolution history because Woodford mudstone with abundant Tasmanites (telalginite) OM had a later and shorter OM conversion and petroleum generation history. More specifically, the dominant pore types developed in Woodford siliceous mudstone changed from bubble-like OM pores in the early bitumen stage, to few bubble-like OM pores and modified mineral pores in the peak bitumen stage, to increased bubblelike OM pores and modified mineral pores in the early oil stage (Tasmanites OM started to convert to petroleum), to dominant modified mineral pores in the oil window stage (full conversion of Tasmanites OM to petroleum), to most abundant modified mineral pores in the early cracking of oil to wetgas stage. It could be seen that the maceral type could also affect the OM pore structure evolution process. Although the quantification of pore structure by manual pore tracing on two SEM images was presented by Ko et al. (2016), shale pore structure evolution process was still mainly qualitatively described and the quantification of FE-SEM images usually could not provide the complete shale pore structure information due to the limited imaging area and resolution.

Thermal simulation experiments were conducted by Wang and Guo (2019) using Jurassic Yanan Formation shale core samples with a TOC of $2.52 \%$, type III kerogen and $0.5 \% \mathrm{R}_{\mathrm{o}}$ collected from the western margin of the Ordos Basin. Hydrous pyrolysis experiments were conducted at 10 temperature points from 200 to $650{ }^{\circ} \mathrm{C}$ with $50{ }^{\circ} \mathrm{C}$ intervals and the amount of hydrocarbons generated at each temperature point was measured. In addition, the shale pore structure of artificially heated samples was characterized qualitatively by FE-SEM and the whole-aperture quantitative pore structure characterization was achieved by combining $\mathrm{CO}_{2}$ (for micropore), $\mathrm{N}_{2}$ (for mesopore) and MIP (for macropore). Finally, Wang and Guo (2019) established a shale pore structure evolution model with four stages: (1) $R_{0} \leq 0.7 \%$ : Due to compaction, micropores decreased slowly while mesopores, macropores 


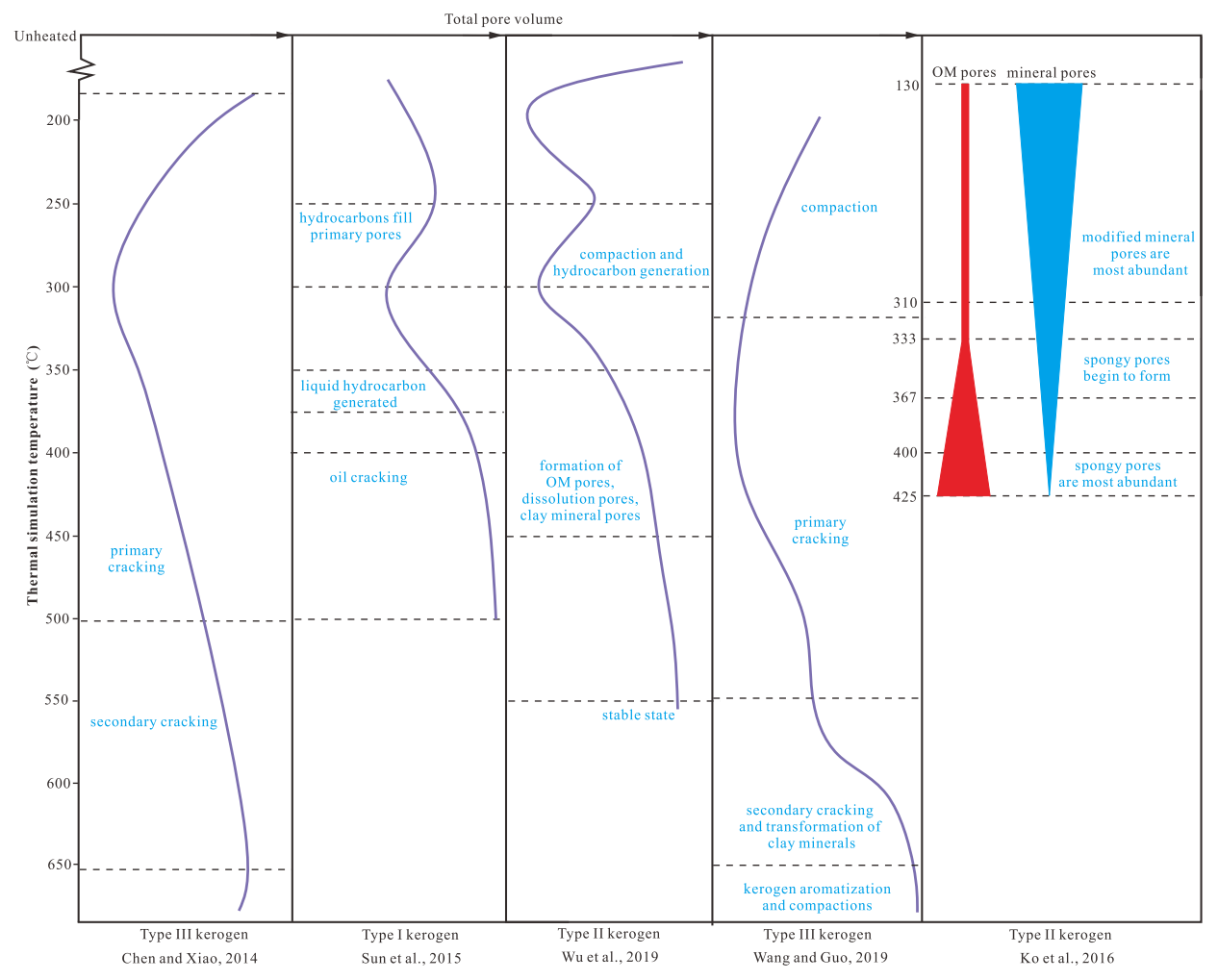

Fig. 2. Pore structure evolution models proposed by different scholars using thermal simulation experiments.

and total pores were reduced rapidly. (2) $0.7 \% \leq \mathrm{R}_{0} \leq 1.6 \%$ : The hydrocarbon generation by $\mathrm{OM}$ controlled the pore structure evolution in this stage. The total pores decreased rapidly first and reached a minimum at $0.78 \% \mathrm{R}_{\mathrm{o}}$ and then increased slowly. More specifically, micropores and mesopores showed similar changing trend with total pores while macropores increased slowly during this stage. The rapid decrease of micropores was caused by the infilling of bitumen generated from kerogen pyrolysis and the later increase of mircopores was because of the cracking of bitumen and the release of hydrocarbon. The decrease of mesopores was caused by both compaction and bitumen infilling. The dissolution of unstable minerals (e.g., feldspar) by organic acids produced during the thermal evolution of OM and the shrinkage cracks formed during hydrocarbon generation caused the increase of mesopores and macropores. High pore pressures generated by hydrocarbon generation and thermal cracking of hydrocarbons in the subsurface could resist compaction and might be another reason for the increase of mesopores and macropores. (3) $1.6 \% \leq \mathrm{R}_{0} \leq 2.3 \%$ : The hydrocarbon generation by $\mathrm{OM}$ and the transformation of clay minerals controlled the pore structure evolution in this stage. The micorpores decreased first and then increased while the mesopores increased first and then decreased. The macropores increased rapidly and the total pores increased steadily. The decrease of micropores was caused by the combination of micropores to mesopores and the later increase of micropores was due to the solid bitumen with abundant micropores generated by kerogen polycondensation in this stage. The combination of micropores, the illitization, the shrinkage of smectite due to dehydration and the dissolution caused the first increase of mesopores. The later decrease of mesopores was caused by the combination of mesopores into macropores. The increase of macropores was caused by the combination of mesopores into macropores, the illitization, the shrinkage of smectite due to dehydration and the dissolution. (4) $R_{0} \geq 2.3 \%$ : The total pores increased to the maximum value and then decreased due to pore blockage during the aggravation of kerogen aromatization and the pore collapse under the increasing external pressure.

Although not exactly modeling the shale pore structure evolution process under geological conditions with lower temperature, very long time period and complicated geofluid systems, thermal simulation experiment is still a practical method to obtain a series of shale samples with same compositions and different maturities in the laboratory. However, the proposed shale pore structure evolution models are largely dependent on the used shale samples and the experimental conditions (Fig. 2; Table 2). It is unrealistic to conduct lots of thermal simulation experiments on shale samples with many lithofacies due to the high cost of thermal simulation experiments.

\section{Conclusion}

Thermal evolution of OM includes hydrocarbon generation, migration and thermal cracking of hydrocarbon. The primary and secondary cracking of OM could increase the OM pore spaces while the pore filling of generated bitumen may lead to the decrease of inorganic and OM pore spaces. Different types of kerogen always show different hydrocarbon generation history during thermal maturation and then lead to different 
Table 2. The shale pore structure evolution stages and controlling factors indicated from thermal simulation experiments in the literature.

\begin{tabular}{|c|c|c|c|c|c|}
\hline Formation name & Experimental conditions & Stage & Pore evolution & Main factors & Reference \\
\hline \multirow{3}{*}{$\begin{array}{l}\text { Upper Permian outcrop; } \\
\text { Oligocene deposit }\end{array}$} & \multirow{3}{*}{$\begin{array}{l}\text { anhydrous; } 300 \sim 7500^{\circ} \mathrm{C} \\
\left(\mathrm{R}_{\mathrm{o}}: 0.69 \% \sim 4.19 \%\right)\end{array}$} & $0.6 \%<\operatorname{Ro}<2.0 \%$ & $\begin{array}{l}\text { pore volume decreased and } \\
\text { then increased }\end{array}$ & $\begin{array}{l}\text { oil generation and thermal cracking; } \\
\text { pore filling in oil-prone shales }\end{array}$ & \multirow{3}{*}{ Chen and Xiao, 2014} \\
\hline & & $2.0 \%<\mathrm{R}_{\mathrm{o}}<3.5 \%$ & pore volume increased rapidly & thermal cracking of kerogen & \\
\hline & & $\mathrm{R}_{\mathrm{o}}>3.5 \%$ & $\begin{array}{l}\text { microporosity decreased and } \\
\text { mesoporosity increased }\end{array}$ & conversion and destruction of $\mathrm{OM}$ pores & \\
\hline \multirow[b]{2}{*}{ Yanchang Formation } & \multirow{2}{*}{$\begin{array}{l}\text { hydrous; } 250 \sim 500^{\circ} \mathrm{C} \text {; } \\
\text { lithostatic pressure: } 100 \mathrm{MPa} \text {, } \\
\text { hydrodynamic pressure: } 50 \mathrm{MPa}\end{array}$} & & & & \multirow[b]{2}{*}{ Sun et al., 2015} \\
\hline & & $350 \sim 375^{\circ} \mathrm{C}$ & secondary pores were produced & hydrocarbon generation & \\
\hline \multirow{4}{*}{$\begin{array}{l}\text { Yanchang Formation; } \\
\text { Xiamaling Formation; } \\
\text { Lucaogou Formation }\end{array}$} & \multirow{4}{*}{$350 \sim 550^{\circ} \mathrm{C} ; 70,80,90 \mathrm{MPa}$} & $\mathrm{R}_{\mathrm{o}}<0.5 \%$ & decreased rapidly & compaction & \multirow{4}{*}{ Wu et al., 2015, 2019} \\
\hline & & $250 \sim 300^{\circ} \mathrm{C}$ & $\begin{array}{l}\text { IP decreased; OP increased and } \\
\text { then decreased }\end{array}$ & compaction; hydrocarbon generation & \\
\hline & & $350 \sim 450{ }^{\circ} \mathrm{C}$ & increased rapidly & $\begin{array}{l}\text { formation of OM pores, dissolution } \\
\text { pores, clay mineral pores }\end{array}$ & \\
\hline & & $550^{\circ} \mathrm{C}$ & stable & $\begin{array}{l}\text { weak thermal cracking of OM, } \\
\text { the enhanced stability of shale } \\
\text { framework and the stable fluid } \\
\text { environment }\end{array}$ & \\
\hline \multirow{3}{*}{ Boquillas Formation } & \multirow{3}{*}{$\begin{array}{l}\text { anhydrous; } 130 \sim 425^{\circ} \mathrm{C} \text {; } \\
68.95 \mathrm{MPa}\end{array}$} & $130 \sim 4310^{\circ} \mathrm{C}$ & $\begin{array}{l}\text { modified mineral pores were } \\
\text { the dominant pore type }\end{array}$ & bitumen generation & \multirow{3}{*}{ Ko et al., 2016} \\
\hline & & $333 \sim 367^{\circ} \mathrm{C}$ & $\begin{array}{l}\text { the spongy OM pores increased } \\
\text { but the modified mineral } \\
\text { pores and primary IP decreased }\end{array}$ & early oil and oil window & \\
\hline & & $400 \sim 425^{\circ} \mathrm{C}$ & $\begin{array}{l}\text { the modified mineral pores and } \\
\text { nanometer-sized spongy OM } \\
\text { pores were dominant pore types }\end{array}$ & $\begin{array}{l}\text { peak oil generation and } \\
\text { cracking of oil to gas }\end{array}$ & \\
\hline \multirow{5}{*}{ Yanan Formation } & \multirow{5}{*}{ hydrous; $200 \sim 650^{\circ} \mathrm{C}$} & $\mathrm{R}_{\mathrm{o}} \leq 0.7 \%$ & $\begin{array}{l}\text { micropores decreased slowly while } \\
\text { mesopores, macropores and total } \\
\text { pores reduced rapidly }\end{array}$ & compaction & \multirow{5}{*}{ Wang and Guo, 2019} \\
\hline & & $0.7 \% \leq \mathrm{R}_{\mathrm{o}} \leq 1.6 \%$ & $\begin{array}{l}\text { micropores, mesopores and total } \\
\text { pores decreased rapidly and } \\
\text { then increased slowly; }\end{array}$ & $\begin{array}{l}\text { hydrocarbon generation; dissolution; } \\
\text { shrinkage cracks }\end{array}$ & \\
\hline & & & macropores increased slowly & & \\
\hline & & $1.6 \% \leq \mathrm{R}_{\mathrm{o}} \leq 2.3 \%$ & $\begin{array}{l}\text { micropore decreased and then } \\
\text { increased; mesopore increased and } \\
\text { then decreased; macropores and } \\
\text { total pores increased }\end{array}$ & $\begin{array}{l}\text { hydrocarbon generation; formation of } \\
\text { solid bitumen; transformation of } \\
\text { clay minerals }\end{array}$ & \\
\hline & & $\mathrm{R}_{\mathrm{o}} \geq 2.3 \%$ & total pores increased and then decreased & pore blockage and collapse. & \\
\hline
\end{tabular}


pore structure evolution characteristics. In addition, Lohr et al. (2015) observed the common existence of primary OM pores in immature shale samples, which depended on the OM type and affected the following OM pore development at higher thermal maturities. Consequently, the OM pores were not only generated by thermal evolution of OM but also could be inherited from their parent OM. However, few studies have been conducted to investigate the pore structure evolution process of different types of OMs.

Inorganic diagenesis mainly consists of compaction, dissolution, and transformation of clay minerals. And the mineral composition of shale significantly affects inorganic diagenesis. Compaction decreases pore spaces significantly during the immature stage and continues to decrease pore spaces during the whole evolution process at different levels. Dissolution of unstable minerals by generated organic fluids creates new pore spaces. However, the role of transformation of clay minerals in pore structure evolution is still disputable, which requires more investigations.

Consequently, the inorganic and organic diagenesis simultaneously control the shale pore structure evolution process, which complicates the revealing of shale pore structure evolution. Furthermore, Liu et al. (2017) discussed the influence of tectonic characteristics on shale pore structure, which expanded the research content of shale pore structure evolution to a larger scale and requires more targeted investigations. Pore structure comparison of a series of natural shale samples with different thermal maturities and similar shale compositions using quantitative (mainly $\mathrm{CO}_{2}$ adsorption, $\mathrm{N}_{2}$ adsorption, MIP) and qualitative (mainly FE-SEM) pore structure characterization instruments is commonly used to investigate shale pore structure evolution characteristics. However, due to the strong heterogeneity of shale and complicated diagenesis, minor difference in shale compositions may cause quite different evolution characteristics, which makes the reliability of this method dependent on the accurate selection of shale samples.

Obtaining a series of shale samples with different thermal maturities using thermal simulation experiments could resolve the issue of shale composition difference. It should be noted that investigating shale pore structure evolution by statistical comparison of FE-SEM images of different sample blocks is somewhat subjective due to the limited imaging areas of FESEM and the representative issue of used images. In order to avoid this problem, the 'in-situ' observation method of pore structure evolution proposed by $\mathrm{Wu}$ et al. (2015) is a relatively ideal way to show the pore structure evolution process directly. However, it is almost impossible to set up thermal simulation experimental conditions exactly same with the real underground conditions (e.g., complicated geofluid systems), which is the main weakness of this method. Consequently, it is better to combine these two methods together in order to obtain more reliable shale pore structure evolution characteristics in future investigations. As the imaging resolution significantly affects the shale pore structure characterization result, the imaging instruments with higher resolution $(\leq 1 \mathrm{~nm})$ should be developed and applied in future studies.

\section{Acknowledgement}

This research was supported by the National Science and Technology Major Project of China (No. 2016ZX05034-001 and No. 2017ZX05035-002), and the National Natural Science Foundation of China (No. 41972145), as well as the Foundation (No. PRP/indep-3-1707 and No. PRP/indep-3-1615) of State Key Laboratory of Petroleum Resources and Prospecting from China University of Petroleum in Beijing.

\section{Conflict of interest}

The authors declare no competing interest.

Open Access This article, published at Yandy Scientific Press on behalf of the Division of Porous Flow, Hubei Province Society of Rock Mechanics and Engineering, is distributed under the terms and conditions of the Creative Commons Attribution (CC BY-NC-ND) license, which permits unrestricted use, distribution, and reproduction in any medium, provided the original work is properly cited.

\section{References}

Alfe, M., Apicella, B., Barbella, R., et al. Structure-property relationship in nanostructures of young and mature soot in premixed flames. Proc. Combust. Inst. 2009, 32(1): 697-704.

Bahadur, J., Radlinski, A.P., Melnichenko, Y.B., et al. Small-angle and ultrasmall-angle neutron scattering (SANS/USANS) study of New Albany Shale. A treatise on microporosity. Energy Fuels 2015, 29(2): 567-576.

Chalmers, G.R., Bustin, R.M., Power, I.M. Characterization of gas shale pore systems by porosimetry, pycnometry, surface area, and field emission scanning electron microscopy/transmission electron microscopy image analyses: Examples from the Barnett, Woodford, Haynesville, Marcellus, and Doig units. AAPG Bull. 2012, 96(6): 1099-1119.

Clarkson, C.R., Jensen, J., Pedersen, L.P.K., et al. Innovative methods for flow-unit and pore-structure analyses in a tight siltstone and shale gas reservoir. AAPG Bull. 2012, 96(2): 355-374.

Clarkson, C.R., Solano, N., Bustin, R.M., et al. Pore structure characterization of North American shale gas reservoirs using USANS/SANS, gas adsorption, and mercury intrusion. Fuel 2013, 103: 606-616.

Chen, J., Xiao, X. Evolution of nanoporosity in organic-rich shales during thermal maturation. Fuel 2014, 129: 173181.

Connan, J. Time-temperature relation in oil genesis: Geologic notes. AAPG Bull. 1974, 58(12): 2516-2521.

Curtis, J.B. Fractured shale-gas systems. AAPG Bull. 2002, 86(11): 1921-1938.

Curtis, M.E., Ambrose, R.J., Sondergeld, C.H. Structural characterization of gas shales on the micro- and nanoscales. Paper SPE137693-MS Presented at Canadian Unconventional Resources and International Petroleum Conference, Calgary, Alberta, Canada, 19-21 October, 2010.

Curtis, M.E., Ambrose, R.J., Sondergeld, C.H., et al. Investigation of the relationship between organic porosity 
and thermal maturity in the Marcellus Shale. Paper SPE144370 Presented at North American Unconventional Gas Conference and Exhibition, the Woodlands, Texas, USA, 14-16 June, 2011.

Curtis, M.E., Cardott, B.J., Sondergeld, C.H., et al. Development of organic porosity in the Woodford Shale with increasing thermal maturity. Int. J. Coal Geol. 2012, 103: 26-31.

Dai, J., Zou, C., Liao, S., et al. Geochemistry of the extremely high thermal maturity Longmaxi shale gas, southern Sichuan Basin. Org. Geochem. 2014, 74: 3-12.

Dewhurst, D.N., Aplin, S.C., Sarda, J.P., et al. Compactiondriven evolution of porosity and permeability in natural mudstones: An experimental study. J. Geophys. Res. 1998, 103(B1): 651-661.

Dewhurst, D.N., Yang, Y., Aplin, A.C. Permeability and fluid flow in natural mudstones. Geol. Soc. London Special Pub. 1999, 158: 23-43.

Dong, T., Harris, N.B., McMillan, J.M., et al. A model for porosity evolution in shale reservoirs: An example from the Upper Devonian Duvernay Formation, Western Canada Sedimentary Basin. AAPG Bull. 2019, 103(5): 1017-1044.

Dong, T., Harris, N.B. The effect of thermal maturity on porosity development in the Upper DevonianLower Mississippian Woodford Shale, Permian Basin, US: Insights into the role of silica nanospheres and microcrystalline quartz on porosity preservation. Int. J. Coal Geol. 2020, 217: 103346.

Föllmi, K.B. The phosphorus cycle, phosphogenesis and marine phosphate-rich deposits. Earth-Sci. Rev. 1996, 40(1-2): 55-124.

Freed, R.L., Peacor, D.R. Geopressured shale and sealing effect of smectite to illite transition. AAPG Bull. 1989, 73(10): 1223-1232.

Gao, Z., Fan, Y., Hu, Q., et al. A review of shale wettability characterization using spontaneous imbibition experiments. Mar. Pet. Geol. 2019, 109: 330-338.

Gao, Z., Hu, Q. Pore structure and spontaneous imbibition characteristics of marine and continental shales in China. AAPG Bull. 2018, 102(10): 1941-1961.

Hatch, C.D., Wiese, J.S., Crane, C.C., et al. Water adsorption on clay minerals as a function of relative humidity: Application of bet and freundlich adsorption models. Langmuir 2012, 28(3): 1790-1803.

Jarvie, D.M., Hill, R.J., Ruble, T.E., et al. Unconventional shale-gas systems: The Mississippian Barnett Shale of north-central Texas as one model for thermogenic shalegas assessment. AAPG Bull. 2007, 91(4): 475-499.

Javadpour, F., Moravvej Farshi, M., Amrein, M. Atomic-force microscopy: A new tool for gas-shale characterization. J. Can. Pet. Technol. 2012, 51(4): 236-243.

Klaver, J., Desbois, G., Littke, R., et al. BIB-SEM characterization of pore space morphology and distribution in postmature to overmature samples from the Haynesville and Bossier Shales. Mar. Pet. Geol. 2015, 59: 451-466.

Ko, L.T., Loucks, R.G., Zhang, T., et al. Pore and pore network evolution of Upper Cretaceous Boquillas (Eagle Ford- equivalent) mudrocks: Results from gold tube pyrolysis experiments. AAPG Bull. 2016, 100(11): 1693-1722.

Ko, L.T., Ruppel, S.C., Loucks, R.G., et al. Pore-types and pore-network evolution in Upper Devonian-Lower Mississippian Woodford and Mississippian Barnett mudstones: Insights from laboratory thermal maturation and organic petrology. Int. J. Coal Geol. 2018, 190: 3-28.

Kuila, U., Prasad, M. Specific surface area and pore-size distribution in clays and shales. Geophys. Prospect. 2013, 61(2): 341-362.

Liu, B., Wang, H., Fu, X., et al. Lithofacies and depositional setting of a highly prospective lacustrine shale oil succession from the Upper Cretaceous Qingshankou Formation in the Gulong Sag, northern Songliao Basin, Northeast China. AAPG Bull. 2019, 103(2): 405-432.

Liu, W., Zhang, C., Gao, G., et al. Controlling factors and evolution laws of shale porosity in Longmaxi Formation, Sichuan Basin. Acta Petrolei Sinica 2017, 38(2): 175184. (in chinese)

Löhr, S.C., Baruch, E.T., Hall, P.A., et al. Is organic pore development in gas shales influenced by the primary porosity and structure of thermally immature organic matter? Org. Geochem. 2015, 87: 119-132.

Loucks, R.G., Reed, R.M., Ruppel, S.C., et al. Morphology, genesis, and distribution of nanometer-scale pores in siliceous mudstones of the mississippian barnett shale. J. Sediment. Res. 2009, 79(12): 848-861.

Loucks, R.G., Reed, R.M., Ruppel, S.C., et al. Spectrum of pore types and networks in mudrocks and a descriptive classification for matrix-related mudrock pores. AAPG Bull. 2012, 96(6): 1071-1098.

Mastalerz, M., Schimmelmann, A., Drobniak, A., et al. Porosity of devonian and mississippian new albany shale across a maturation gradient: Insights from organic petrology, gas adsorption, and mercury intrusion. AAPG Bull. 2013, 97(10): 1621-1643.

Mathia, E.J., Bowen, L., Thomas, K.M., et al. Evolution of porosity and pore types in organic-rich, calcareous, Lower Toarcian Posidonia Shale. Mar. Pet. Geol. 2016, 75: 117-139.

Milliken, K.L., Rudnicki, M., Awwiller, D.N., et al. Organic matter-hosted pore system, Marcellus formation (Devonian), Pennsylvania. AAPG Bull. 2013, 97(2): 177-200.

Pan, L., Xiao, X., Tian, H., et al. Geologicalmodels of gas in place of the Longmaxi shale in southeast Chongqing, south China. Mar. Pet. Geol. 2016, 73: 433-444.

Pearce, R.B., Clayton, T., Kemp, A.E.S. Illitization and organic maturity in Silurian sediments from the Southern Uplands of Scotland. Clay Min. 1991, 26(2): 199-210.

Raiswell, R. The microbiological formation of carbonate concretions in the Upper Lias of NE England. Chem. Geol. 1976, 18(3): 227-244.

Rexer, T.F., Mathia, E.J., Aplin, A., et al. High-pressure methane adsorption and characterization of pores in Posidonia Shales and isolated kerogens. Energy Fuels 2014, 28(5): 2886-2901.

Ross, D.J.K., Bustin, R.M. Shale gas potential of the Lower Jurassic Gordondale Member, northeastern British 
Columbia, Canada. Bull. Can. Pet. Geol. 2007, 55(1): 51-75.

Ross, D.J.K., Bustin, R.M. Characterizing the shale gas resource potential of Devonian-Mississippian strata in the Western Canada sedimentary basin: Application of an integrated formation evaluation. AAPG Bull. 2008, 92(1): 87-125.

Ross, D.J.K., Bustin, R.M. The importance of shale composition and pore structure upon gas storage potential of shale gas reservoirs. Mar. Pet. Geol. 2009, 26(6): 916-927.

Sarmiento, M.F., Rouzaud, J.N., Bernard, S., et al. Evolution of Barnett Shale organic carbon structure and nanostructure with increasing maturation. Org. Geochem. 2014, 71: 7-16.

Sing, K.S.W. Reporting physisorption data for gas/solid systems with special reference to the determination of surface area and porosity. Pure Appl. Chem. 1985, 57(4): 603-619.

Slatt, R.M., OBrien, N.R. Pore types in the Barnett and Woodford gas shales: Contribution to understanding gas storage and migration pathways in fine-grained rocks. AAPG Bull. 2011, 95(12): 2017-2030.

Sun, L., Tuo, J., Zhang, M., et al. Formation and development of the pore structure in Chang 7 member oil-shale from Ordos Basin during organic matter evolution induced by hydrous pyrolysis. Fuel 2015, 158: 549-557.

Sweeney, J.J., Burnham, A.K. Evaluation of a simple model of vitrinite reflectance based on chemical kinetics. AAPG Bull. 1990, 74(10): 1559-1570.

Wang, F., Guan, J., Feng, W., et al. Evolution of overmature marine shale porosity and implication to the free gas volume. Pet. Explor. Dev. 2013, 40(6): 819-824.

Wang, F., Guo, S. Influential factors and model of shale pore evolution: A case study of a continental shale from the Ordos Basin. Mar. Pet. Geol. 2019, 102: 271-282.

Wang, P., Jiang, Z., Chen, L., et al. Pore structure characterization for the Longmaxi and Niutitang shales in the Upper Yangtze Platform, South China: Evidence from focused ion beam-He ion microscopy, nano-computerized tomography and gas adsorption analysis. Mar. Pet. Geol. 2016, 77: 1323-1337.

Waples, D.W. Time and temperature in petroleum formation: application of Lopatin's method to petroleum exploration: Reply1. AAPG Bull. 1982, 66(8): 1152.

Wilkin, R.T., Arthur, M.A., Dean, W.E. History of water column anoxia in the Black Sea indicated by pyrite framboids size distributions. Earth Planet. Sci. Lett. 1997, 148(3-4): 517-525.

Wilkin, R.T., Barnes, H.L., Brantley, S.L. The size distribution of framboidal pyrite in modern sediments: An indicator of redox conditions. Geochim. Cosmochim. Acta 1996, 60(20): 3897-3912.

Wood, D.A., Hazra, B. Pyrolysis S2-peak characteristics of Raniganj shales (India) reflect complex combinations of kerogen kinetics and other processes related to different levels of thermal maturity. Adv. Geo-Energy Res. 2018, 2(4): 343-368.

Wood, D.A. Establishing credible reaction-kinetics distributions to fit and explain multi-heating rate S2 pyrolysis peaks of kerogens and shales. Adv. Geo-Energy Res. 2019, 3(1): 1-28.

Wu, S., Yang, Z., Zhai, X., et al. An experimental study of organic matter, minerals and porosity evolution in shales within high-temperature and high-pressure constraints. Mar. Pet. Geol. 2019, 102: 377-390.

Wu, S., Zhu, R., Cui, J., et al. Characteristics of lacustrine shale porosity evolution, Triassic Chang 7 member, Ordos Basin, NW China. Pet. Explor. Dev. 2015, 42(2): 185195.

Yang, R., Jia, A., He, S., et al. Water adsorption characteristics of organic-rich Wufeng and Longmaxi Shales, Sichuan Basin (China). J. Pet. Sci. Eng. 2020, 193: 107387.

Zhao, H., Givens, N.B., Curtis, B. Thermal maturity of the Barnett Shale determined from well-log analysis. AAPG Bull. 2007, 91(4): 535-549.

Zhou, L., Kang, Z. Fractal characterization of pores in shales using NMR: A case study from the LowerCambrian Niutitang Formation in the Middle Yangtze Platform, Southwest China. J. Nat. Gas Sci. Eng. 2016, 35: 860872.

Zou, C., Dong, D., Wang, S., et al. Geological characteristics and resource potential of shale gas in China. Pet. Explor. Dev. 2010, 37(6): 641-653. 